\title{
A Van Hiele Theory analysis for teaching volume of three- dimensional geometric shapes
}

\author{
Eunice Kolitsoe Moru ${ }^{*}$, Maqoni Malebanye ${ }^{2}$, Nomusic Morobe ${ }^{3}$, Mosotho Joseph George ${ }^{4}$ \\ ${ }^{1}$ Department of Mathematics and Computer Science, National University of Lesotho, Lesotho \\ ${ }^{2}$ John Maund High School, Maseru, Lesotho \\ ${ }^{3}$ Department of Science Education, National University of Lesotho, Lesotho \\ ${ }^{4}$ Department of Chemistry and Chemical Technology, National University of Lesotho, Lesotho \\ *Corresponding author: ekmoru@yahoo.com
}

\section{ARTICLE INFO}

\section{Article History:}

Received: 30 July 2020

Revised: 27 October 2020

Accepted: 2 November 2020

Published online: 16

December 2020

Published Regularly: January 2021

\section{Keywords:}

Geometry, 2-dimensional shapes, 3-dimensional shapes, Van Hiele Theory

\section{ABSTRACT}

Geometry is among the cornerstones of mathematics because of its applicability in real life and its connection to other areas of mathematics. The reported study explored how the volume of 3D geometric shapes was taught in one high school in Lesotho. One male teacher and an intact class of sixty high school students were the participants of the study. The study was exploratory in nature. This was in order to understand the phenomenon under study so as to suggest ways on how to make some improvements for the future. Data were collected through classroom observations, photo shootings, note-taking, and interviews. Classroom observations enabled the researchers to start the analysis while also observing. The photos taken captured the nature of the tasks given to students, some explanations, and class interactions. The Van Hiele theory of geometric thought was used as the framework of analysis. The findings of the study show that at level 1 , the teacher focused mainly on the vocabulary of the concept at hand, the information phase. Another phase which was dominant in the teaching at the same level is the direct orientation. The free-orientation phase was not fully realized. The analysis level was achieved through the information phase and the direct orientation phase. Thus the progression from one level to another by students occurred having some phases of learning being skipped due to the way the instruction was organized. It is postulated that lack of proper understanding of some concepts in geometry by students may result from this kind of instruction.

@ 2020 Universitas Muhammadiyah Surakarta

\section{Introduction}

Geometry is the branch of mathematics that is concerned with the shape of individual objects, spatial relationships among various objects, and their properties (Luneta, 2014; Bora \& Ahmed, 2018). It is an essential area in the school mathematics curriculum worldwide. The study of geometry offers many foundational skills and helps to build the thinking skills of logic, deductive reasoning, analytical reasoning, and problem-solving. Geometry is also linked to many other areas in mathematics such as measurements, algebra, calculus, and trigonometry. It is used in our daily lives by architects, engineers, physicists, land surveyors, and many more professions (Russell, 2014).

\section{To cite this article:}

Moru, E., Malebanye, M., Morobe, N., \& George, M. (2020). A Van Hiele Theory analysis for teaching volume of three-dimensional geometric shapes. JRAMathEdu (Journal of Research and Advances in Mathematics Education), 6(1), 17-31. https://doi.org/10.23917/jramathedu.v6i1.11744 
Because of its importance, a number of research studies have been conducted in either investigating the teachers' geometric pedagogical content knowledge, their subject matter knowledge, and the impact of instruction on students' understanding by using Van Hiele theory of geometric thought (Abu \& Abidin, 2013; Luneta, 2014; Alex \& Mammen, 2016; Robichaux-Davis \& Guarino, 2016; Armah et al.,2018; Armah \& Kissi, 2019). Luneta (2014) investigated student teachers' conceptual knowledge of some basic geometric shapes(polygons, polyhedrons, and their properties) through tests and interviews. Abu and Abidin ( $\underline{2013})$, Alex and Mammen (2016), Armah et al. (2018), and Connolly (2010) studied the impact of Van Hiele based instruction on students' understanding of geometry by giving the students both the pre-test and post-test to find out how the teaching based on the Van Hiele theory impacted their learning. Armah and Kissi (2019) and Robichaux-Davis and Guarino (2016) investigated teachers' geometric pedagogical content knowledge. Armah and Kissi made some classroom observations while Robichaux-Davis and Guarino gave the teachers some test items to respond to. All the mentioned studies found the Van Hiele theory of geometric thought to be a useful tool in the organization of both instruction and data analysis.

What seems to be missing mostly in the reported studies that the current one offers is the idea of observing how the teacher organizes instruction in the real classroom situation in order to witness how the concepts were communicated to students. During these observations, photos of students, the teacher, and classroom tasks written on the board by the teacher were taken and included as part of the presented paper. This is of great importance as an addition to the literature because giving the details of how instruction was implemented gives the reader a clearer picture as to where improvements could be made in the teacher's pedagogy and the subject matter knowledge. The inclusion of photos gives the reader a better picture of witnessing the type of interaction that took place in the classroom between the teacher and students, and the students themselves. The type of questions in the form of interviews that were posed to the teacher after instruction enabled the teacher to reflect more on areas of improvement in teaching. Such discussions were beneficial as they within the framework of the theory that has proved to be useful in teaching geometry (Abu \& Abidin, 2013; Armah et al., 2018; Armah \& Kissi, 2019, Atebe \& Schäfer, 2011).

The Van Hiele Theory is a theory of geometric thought which helps teachers organizes instruction for the effective teaching of geometry (Luneta, 2014; Fitriyani et al., 2018; Amidu \& Nyarko, 2019). This theory consists of two parts, namely, "levels of thinking" and "phases of learning" (Howse \& Howse, 2015). The levels of thinking are levels of understanding through which learners progress as a result of instruction organized into five phases of learning geometry (ibid.). They are visualization, analysis, informal deduction, deduction, and rigor. These levels are sequential and hierarchical (Vojkuvkova, 2012; Amidu \& Nyarko, 2019).

The five phases are: information, directed orientation, explication, free orientation, and integration (to be elaborated under theoretical framework). The Van Hiele theory is not age-dependent. Hence the learners' progression from one level to the next is dependent on the effectiveness of the teaching and content acquisition opportunities that they are exposed to (Luneta, 2014; Robichaux-Davis \& Guarino, 2016; Nisawa, 2018). Thus its application is key to the success of students in studying geometry. 


\section{Statement of the problem}

A number of studies show that most teachers are not fully prepared to teach geometry, in particular, 2D and 3D shapes (Luneta, 2014; Robichaux-Davis \& Guarino, 2016; Armah \& Kissi, 2019). This is indicative in their subject matter knowledge in geometry and the pedagogical content knowledge which is mostly below the requirements of the curriculum for the students they are supposed to teach. In Lesotho, as in other parts of the world (e.g., Ghana, Malaysia, South Africa, United States), geometry is covered at all levels of education. The need for a better conceptual understanding of 2D and 3D shapes and their properties is required at both the secondary and high school levels (Examinations Council of Lesotho Reports, 2017; 2018; Luneta, 2014). This requirement is a necessity as students who do not have a proper understanding of geometry may be disadvantaged in both their further studies and coping with their environment. Part of the solution to the problem could be that of organizing instruction in alignment with the Van Hiele Theory. This theory is associated with the effective teaching of geometry (Connolly, 2010; Luneta, 2014). It is noted that there are very few studies in which teachers were physically observed in teaching geometry using the Van Hiele theory as the framework of analysis. Thus the opportunity of witnessing how the teachers organized instruction was missed. This is also a big problem that needs to be addressed

\section{Research question}

Since the success in learning geometry is dependent on how instruction is organized (Luneta, 2014; Howse \& Howse, 2015), the research question for the reported study was: What kind of instruction does the teacher implement to teach the students the volume of 3D geometric shapes? As this is a case study, an attempt to answer the posed question was sought by observing a teacher in one high school in Lesotho when teaching the volume of 3D shapes. The Van Hiele theory of geometric thought was used as the lens of analysis.

\section{Literature review}

Luneta (2014) investigated the content knowledge of basic geometry with which 128 student teachers (foundation phase) in South Africa enter university. Van Hiele theory of geometric thought was used as the framework of analysis. The findings show that the majority of the participants in the study were operating at level 1 (recognition of shapes by appearance); the same level as the class they were going to teach. This level is said to be lower than that which is expected from the Grade 12 learners who are to be operating at levels 3 (recognition of the importance of properties of shapes and the relationships among them) and 4 (students establish and analyze definitions, axioms, and theorems) at the completion of their studies.

In their study, Robichaux-Davis and Guarino (2016) assessed elementary preservice teachers' knowledge of teaching geometry. This assessment was developed to evaluate three domains, (a) geometry content knowledge, (b) geometry pedagogical content knowledge which included knowledge of appropriate geometric materials and manipulatives, and (c) spatial visualization skills using Van Hiele Levels of geometric thought as the lens. The questions covered the first three levels, visualization, analysis, and informal deduction. The findings of the study show that the teachers had a severe deficit in their understanding of geometry as they operated at first and the second levels only. It is suggested that these teachers lacked the skills to competently teach students of the grades they were supposed to teach. Although these teachers operated at a higher level than those in the study by Luneta ( $\underline{2014})$, they still could not meet the demands of the curriculum.

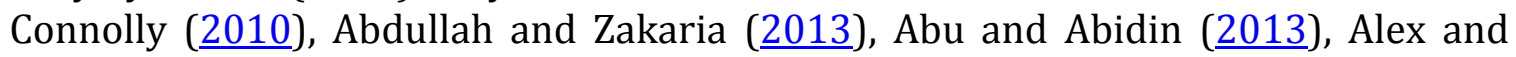

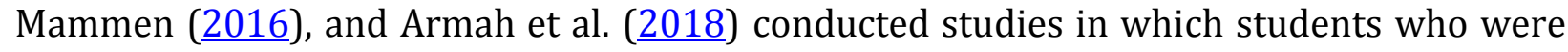


taught using Van Hiele phase-based instruction (characterized by discussion, group work, hands-on investigations, and collaborative learning) managed to transit to higher levels of geometric thinking than their counterparts who were exposed to conventional or traditional methods (where students follow the instructions the teacher gives with no hands-on activities). Before moving on to the next level, students were exposed to instruction that is in alignment with all the phases of learning. These studies demonstrate that the Van Hiele phase-based instruction appeared to have a positive impact on students' geometric thinking and hence has great potential of improving the teaching of geometry in schools than the traditional approach.

Atebe and Schäfer (2011) compared the teaching of geometry in South African and Nigerian high schools with the sample that comprised three mathematics teachers (T1, T2 \& T3) from Nigeria and three mathematics teachers (T4, T5 \& T6) from South Africa. Instructional activities in the six schools were videotaped. The Van Hiele phases of learning descriptors were used as the framework of analysis. The findings of the study show that the South African teachers provided students with learning opportunities that were more aligned to the Van Hiele phases than their Nigerian counterparts. Some of the missing phases observed from the teaching in Nigerian high schools were information (T1, T2 \& T3), explication (T1, T2 \& T3), and integration (T1 \& T3). In South African schools, the missing phases were information (T6), explication (T6), and integration (T4, T5 \& T6). From these findings, it could be postulated that the South African students would have a better conceptual understanding of geometric concepts than Nigerian students.

\section{Theoretical framework}

As it has already been stated, the Van Hiele theory of geometric thought was used as a framework for analysis. Van Hiele had initially classified the levels as $0,1,2,3$, and 4 (Luneta, 2014; Fitriyani et al., 2018; Nisawa, 2018), for ease of referencing the levels 1, 2, 3, 4 , and 5 classification will be used instead as in the case of other researchers (e.g., Howse \& Howse, 2015; Armah \& Kissi, 2019). The description of the levels and phases are presented in Tables 1 and 2, respectively.

\section{Table 1}

Levels of thinking according to Van Hiele Theory of Geometric Thought

Level 1: $\quad$ Students recognize figures by appearance as a whole in different positions or drawing

Visualization

Level 2: Analysis

Level 3:

Informal deduction

Level 4:

Deduction

Level 5:

Rigor (Alex \& Mammen 2018; Armah \& Kissi, 2019).

Students describe shapes on the basis of their properties but not in a logical order (Howse \& Howse, 2015; Fitriyani et al., 2018).

Students recognize the importance of properties and the relationships among them.

They are also expected to present a logical ordering of the properties (Fitriyani et al., 2018).

Learners can apply formal deductive arguments such as proofs and theorems within an axiomatic system. They should also know the role of necessary and sufficient conditions in proof construction (Amidu \& Nyarko, 2019).

Students establish and analyze definitions, axioms, theorems, corollaries, and postulates (Alex \& Mammen, 2018; Robichaux-Davis \& Guarino, 2016).

Table 2

Phases of learning involved in the Van Hiele Theory of Geometric Thought

Information Students' prior knowledge is checked while also developing the vocabulary and concepts for a task. The teacher assesses students' interpretation/reasoning and determines how to move forward with future tasks by laying the foundation (Howse \& Howse, 2015; Alex \& Mammen, 2018). 
Table 2 (continued)

Directed Students actively engage in carefully structured teacher-directed tasks to formally Orientation recognize and verbalize their understanding of the new geometric concepts introduced at the information phase (Howse \& Howse, 2015).

Explication: $\quad$ Students are given the opportunity to verbalize their understanding of the concept at hand. The teacher is responsible for leading the discussion or facilitate the dialogue (Howse \& Howse, 2015; Armah \& Kissi, 2019).

Free orientation Students are challenged with tasks that are more complex, more open-ended, and discover their own ways of completing each task (Armah \& Kissi, 2019).

Integration Students summarise what they have learned, creating an overview of the concept they are dealing with (Armah \& Kissi, 2019). They also use all the concepts to complete the task at hand (Howse \& Howse, $\underline{2015}$ ).

\section{Methods}

The reported case study was exploratory in nature. This is because this design is mostly qualitative in nature and would allow the researchers to collect some rich data related to the phenomenon under study. The aim was to familiarize ourselves with the teaching of geometry in Lesotho high schools so that we could make an informed choice of how to make improvements about the problem of the study. The participants of the study were one male teacher and a class of sixty high school students who were in the final year of their high school education. The teacher was a Diploma in Science Education holder with a ten-year experience of teaching mathematics at the high school level. During his teacher education, the teacher had not been exposed to Van Hiele's phase-based instruction. The knowledge of geometry he had was obtained from high school mathematics education and his own reading of content to be covered in class, as stipulated in the syllabus. The class consisted of 28 males and 32 females within the age range of 19 to 22 years. Upon completion of their high school education, students must have acquired the knowledge and skills required by the first three levels of Van Hiele theory (National Curriculum Development Centre \& Examinations Council of Lesotho, 2019). Their prior knowledge in geometry included 2D shapes, their names, properties, and how to find their area. In addition, they knew how to apply the Pythagoras Theorem. The choice of the school in which the study was conducted was purposive. This is because the school was easily accessible in terms of distance. This was, therefore, a convenient choice. The teacher was observed in the way that he organized his instruction in teaching geometry. Data collection was done through video recording classroom observations, photo shootings, note-taking, and interviewing the teacher. The first author and the third took part in the observations and note-taking. The second author focused on taking photos of the important parts of the lessons, while the fourth author was video recording the lessons. The issue of reliability is addressed by giving verbatim accounts of the participants. In addition the activities that were given to students by the teacher are shown in the teacher's own handwriting. The permission to conduct the study was sought from the concerned parties, namely, the teacher, the students, and the principal of the school, both verbally and in writing.

\section{Results and discussion}

Results from the video recorded observed lessons, photo shooting, and audio taped interviews of the teacher are now presented. As highlighted earlier, the teacher taught the topic in three lessons. Thus the presentation will show the analysis of the three lessons ( 1 , 2 , and 3). 


\section{Lesson 1}

The teacher introduced the lesson by reminding the students about the polygons such as triangles, the quadrilaterals, and their different names. He then introduced the polyhedrons indicating that they are called 3D solids/shapes and their faces are made up of polygons. The cube, the cuboids, and the triangular prisms were sketched on the board (see Figure 1). The students were able to describe the drawn shapes based on their appearance indicating that they were exposed to the visualization level of Van Hiele. They were also building up the vocabulary from the 2D shapes which constitute their prior knowledge. This reflects the information phase within the visualization level.

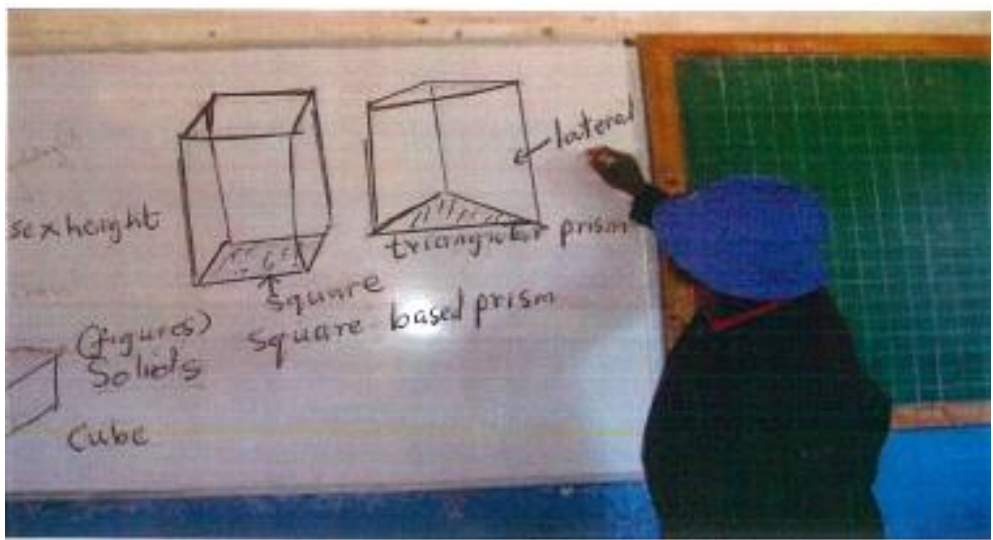

Figure 1. Teacher's diagrams for square-based prisms (cube and cuboids) and a triangular prism

The teacher brought the models of 3D geometric solids/shapes which were made by students of the previous year (Figure 2). When asked in an interview:

Researcher : Why did you bring the models to class while you drew the shapes on the board?

Teacher : I brought the models because I knew that I would not be able to draw the shapes accurately on the board. I can only sketch them and this might not give the students a true picture of what the shapes really look like.

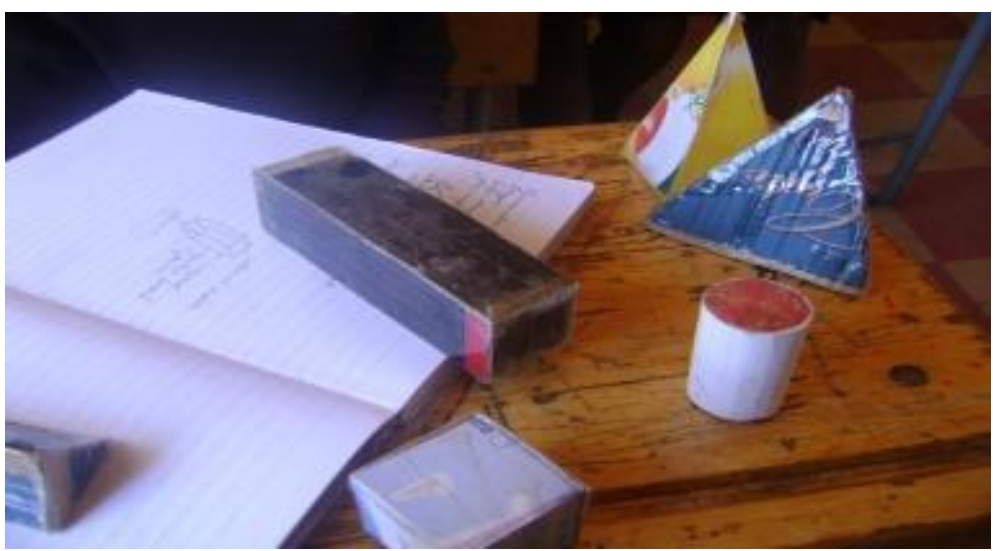

Figure 2. Some models of 3D geometric solids used as teaching aids.

The teacher then held the models one by one in front of the whole class and asked students to give their names. While holding the solids in front of the class, the teacher was moving and rotating them. Students gave their names shouting in chorus, "triangular prism", "square-based prism", but when it came to the cylinder, only a few students responded, "circular-based prism" and the teacher agreed with them that it is circular-based prism and further told them that it is called cylinder. The teacher then held the pyramid and asked students what is its name, students took some time before answering and then said 
"pyramid". This was still part of the visualization level as the shapes were recognized as a whole though in different positions, the information phase (continuing to build up the vocabulary).

Students were then expected to differentiate between the square-based pyramid and the cone. They said that the cone has the circular base while the other had a square base (as the names suggest). This was still the visualization level as the students named the parts of the figure without thinking of these parts as a characteristic of a class of figures. The teacher then drew a table on the board (See Figure 3), wrote the names of the solids, and asked the students to determine the number of vertices, edges, and faces of each.

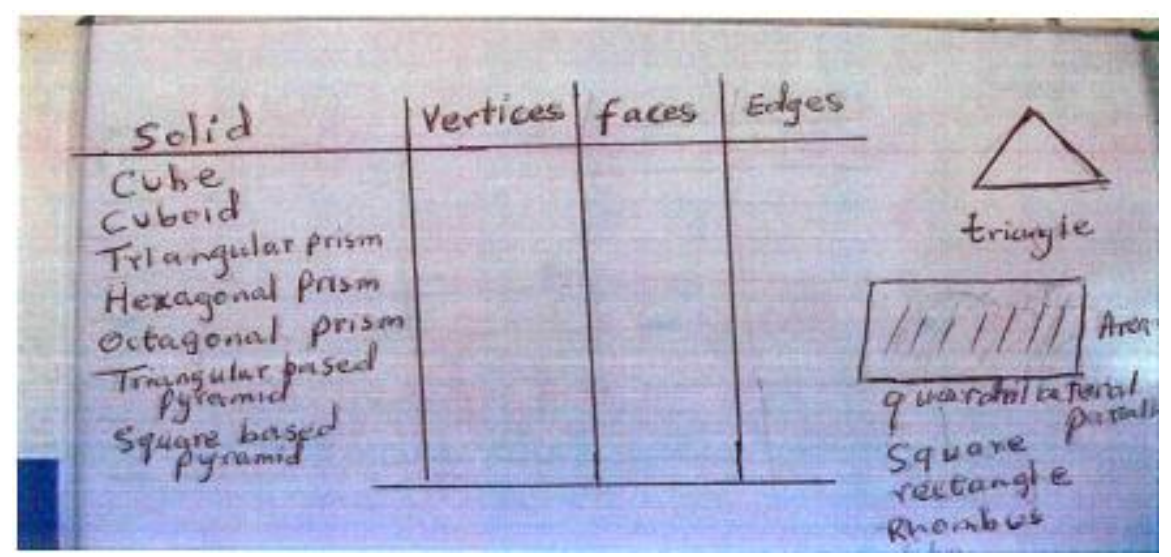

Figure 3. A table to be filled in as a class exercise

Before the students could do the activity, the teacher asked them, "What are the vertices?" then they answered in chorus, "corners". He asked them another question, "What are the edges?" students answered again in chorus and said, "metšetše" (a native language Sesotho word meaning where two faces meet). Students were not able to define the faces, but most of them were able to get the activity correct as it was dependent on recognition of parts of the figure and not on giving definitions per se. The students responded to the given activity both individually and in groups by using the models (Figure 4). Some moved and rotated the shapes while counting the number of edges, vertices, and faces while others drew the 3D shapes in their exercise books before counting. They did so without paying attention to either the sizes of the edges or the faces. This shows that the students were exposed to the guided/directed orientation phase as they were engaged in teacher-directed/guided tasks within the visualization level. The tasks were also structured and not open-ended.

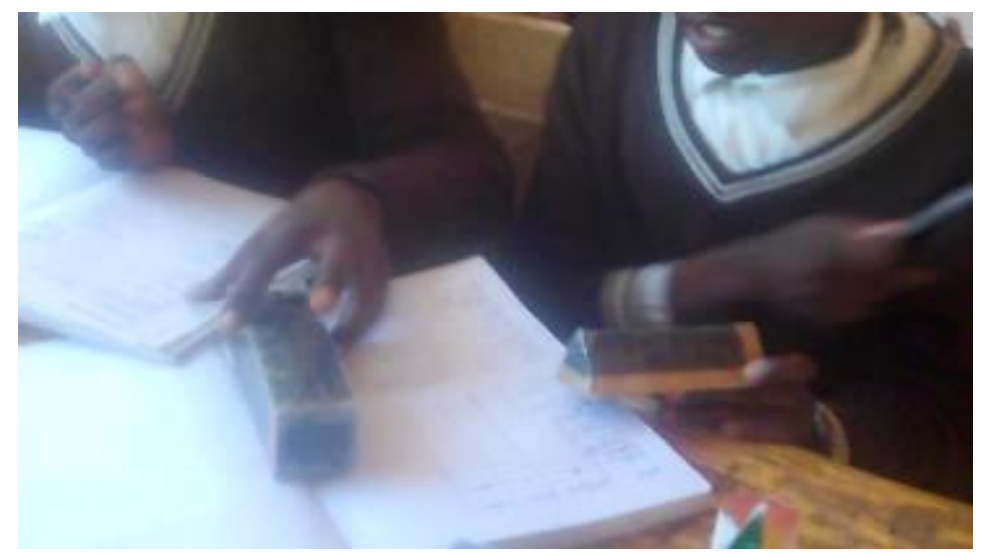

Figure 4. Students using models in counting the number of vertices, edges, and faces 
After assessing the students' work, the teacher filled the table that was drawn on the board. The answers given by students were as follows (vertices, faces, and edges in the given order): Cube, 8, 6, and 12; Cuboid, 8, 6, and 12; Triangular Prism, 6, 5, and 9; Hexagonal Prism, 12, 8, and 18; Octagonal Prism, 16, 10 and 24; Triangular Based Pyramid, 4, 4, and 6; Square Based Pyramid, 5, 5, and 8. Thereafter the teacher asked the students to give the relationship between the vertices, edges, and faces. Students were not able to give the relationship until the teacher gave them a hint. He asked students to give the number of vertices, faces, and edges of a cube. The students answered, "8 vertices, 6 faces, and 12 edges". He then told the students that there is a relationship between vertices, faces, and edges (guided). After this hint was given, one student raised the hand and gave the answer, "number of vertices plus number of faces minus two is equal to number of edges". The question could have been asked as "Is there any relationship between the edges, faces, and vertices?" in order to qualify to be a free orientation problem without a hint being given by the teacher. The way the question was asked was suggestive that there is a relationship between the edges, faces, and vertices. It could be taken as half-open. A hint given also made the answer not to qualify to have been obtained without some guidance. This is because it was not given using a series of sets of numbers that qualify to form a pattern from which a generalization could be made, such as referring to all the answers given in the completed table in Figure 3. The students were not given the opportunity to verbalize what they understand a prism to be, a concept at hand (explication). They were also not given the opportunity to summarize the content of the lesson (integration).

\section{Lesson 2}

The teacher introduced the lesson by reminding the students about 2D and 3D figures, drew a 4 by 4 grid on the board (made of small squares), and asked students how many small squares they see in the bigger one. Students answered in chorus, "sixteen." Some said that they do not see how the number 16 was found. The teacher showed the students how the 16 was obtained by counting the small squares inside the larger one. He then drew the square on the board and drew the diagonal to cut it into two triangles then showed the students how to find the area of a triangle. The teacher referred back to polyhedrons, particularly square-based prism. He explained the structure of square-based prism (showed the students parallel faces and lateral faces then told them that those parallel sides are the cross-sections). This shows that the teacher organized instruction in line with the information phase of the analysis level of Van Hiele theory, which is the second level. He described the shapes on the bases of their properties but not in a logical order. During the interview, the teacher was asked:

\section{Researcher : what is the difference between base and cross-section? \\ Teacher : the base and cross-section are used interchangeably depending on the current position of the shape.}

In continuing the lesson, the teacher drew the net of a square-based prism (see Figure 5) and showed students how they could calculate the surface area. The teacher then asked the students to give the name given to circular-based prism whose answer was given by the whole class as a cylinder. He then drew the cylinder on the board and asked the questions resulting in the discussion between him and the students:

Teacher

Student

Teacher

All students
How can we find the total surface area of the cylinder (closed)?

We find the area of two circles, the one on the top and the one at the bottom.

Meaning that we draw the net?

Yes! 
The net includes the rectangle which was not mentioned by the students though acknowledging that it has to be drawn. The teacher then drew the net on the board (see Figure 6) and students could see the two circles, but they could not show the teacher how to calculate the area.

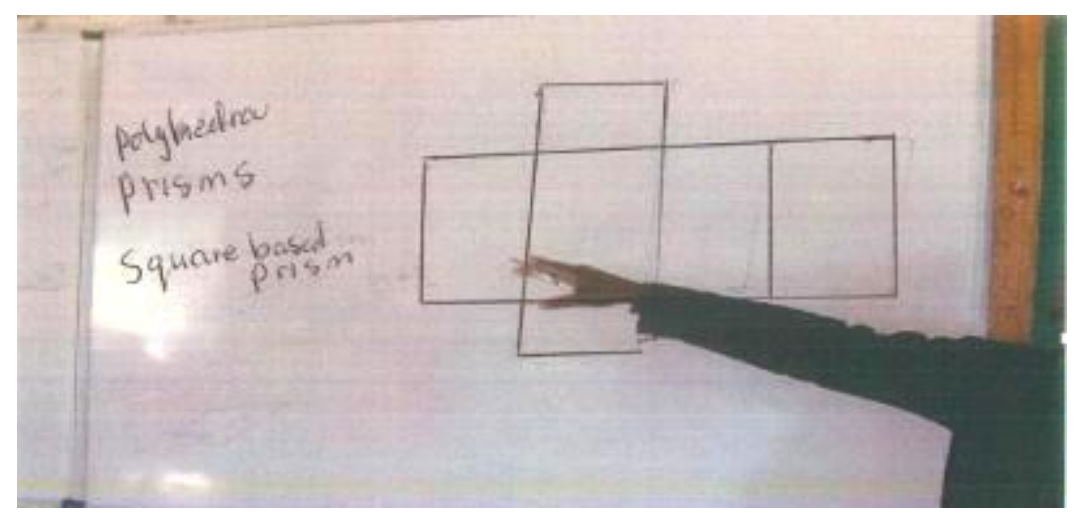

Figure 5. The teacher showing the net of a square-based prism (cuboids)

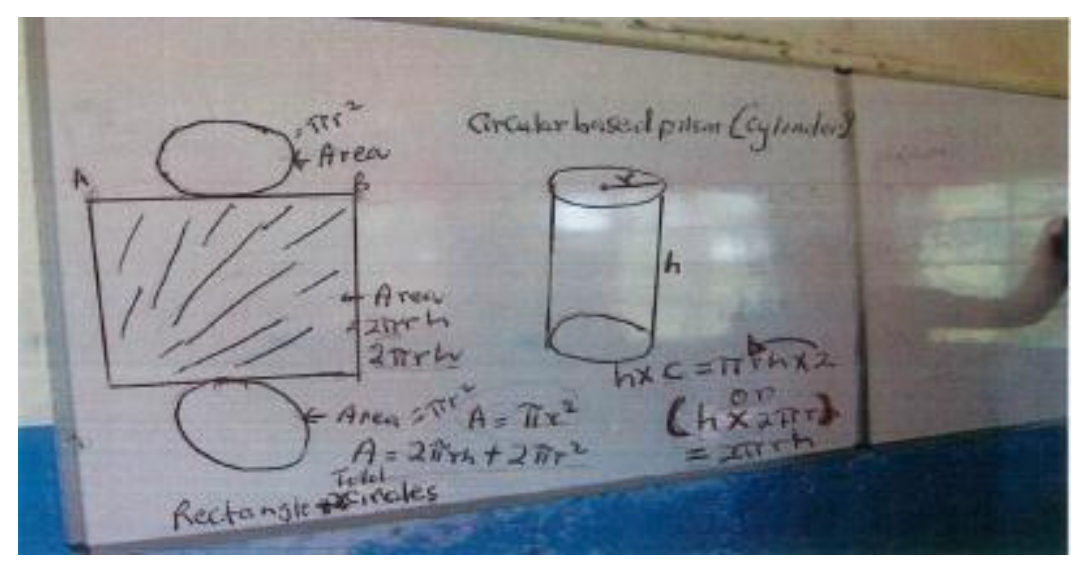

Figure 6. A Cylinder, its net and calculation of surface area

The teacher then gave them the formula for finding area of the circle which they seemed to have forgotten. Some students, however, nodded to show that they now remember the formula. In calculating area of the net, the students could not relate the length of the rectangular part to the circumference of the circle. The teacher ended up showing the students how the total surface area of the cylinder was calculated using the formula of the area of a closed cylinder. One student asked the question regarding the net of a cylinder wanting to know if it would be correct to write the length of the rectangle being the same as the diameter of the circle. Students were asked to explain whether it would be correct or not and one student indicated that it would not be correct, but he was not able to explain why. The teacher then explained it by drawing another cylinder. This showed the directed orientation phase of the analysis level, but not to a greater extent since it was supposed to be done by students on their own. The teacher instructed the students to explain how they could tell if the cylinder is open, closed, or half-open. Students could not give an answer. The teacher demonstrated how to calculate the area of the cylinder in different forms (closed, open, and half-open). He did not probe students any further by at least making reference to the content that students had already been exposed to regarding the concept of cylinder.

In continuing the lesson, the teacher gave an activity on calculating the area of a cuboid, triangular prism, and cylinder (see Figure 7). 


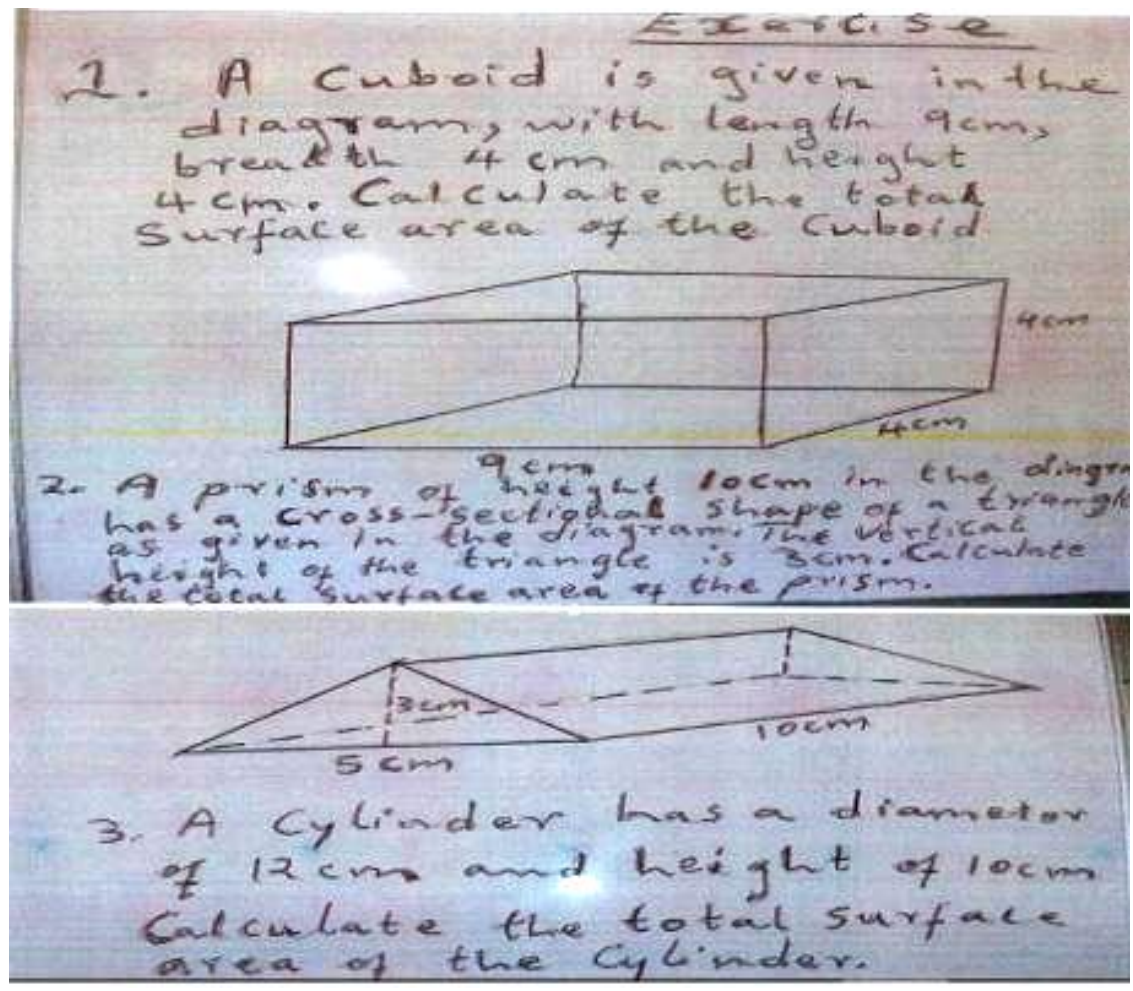

Figure 7. Activity on calculating the area of a cuboid, triangular prism, and a cylinder

When calculating the area of the shapes, students started by drawing the nets, which showed that they were operating at the directed orientation phase of the analysis level. This is because the response to the activity was guided by the teacher. The students, however, managed to use the rules for finding the area of the different components of the nets which constituted the shapes correctly (analysis level). The concept of the area of polygons that the teacher introduced earlier was used when doing this activity. The correct solutions were found to be: Cuboid $(9 \times 4 \times 2+4 \times 4 \times 2+9 \times 4 \times 2=176$ square centimeters); Triangular prism $\left(\left(\frac{1}{2} \times 5 \times 3 \times 2\right)+(5 \times 10)+\sqrt{\left(\frac{1}{2}(5)\right)^{2}+3^{2}} \times 10 \times 2=\right.$ 143.1 square centimetres) and a cylinder $\left(\frac{22}{7} \times 6^{2} \times 2+2 \times \frac{22}{7} \times 6 \times 10=\frac{4224}{7}\right.$ square centimeters). The assumption made was that it is a closed cylinder, as the teacher clarified when the students were engaged in the activity. An approximation of $\pi$ was taken to be $\frac{22}{7}$. The teacher then summarized the lesson by showing the students that in order to find the area of 3D, one should use the concept of the area of polygons because 3D shapes are made up of polygons (2D shapes). This could have been the integration phase of learning if the summary was done by students, but the teacher decided to do it instead. The interview with the teacher transpired as follows:

Researcher : Why did you teach the area concept before the volume concept?

Teacher : I taught the area first because I wanted to link it with the volume concept. Students could find it easy to calculate the volume when they know how to calculate the area.

Researcher : What do you mean by that?

Teacher : : To find the volume of solids, we take the area of the base and multiply it by height. If it has the cross-section, we multiply the area of the cross-section by length. So the area is important. 
In this lesson, the explication phase, free orientation phase, and integration phase of the analysis level were not reflected.

\section{Lesson 3}

The teacher introduced the lesson by asking students to define the word "capacity." Students could not define it and the teacher ended up defining it as "the total amount of substance the object can hold". The students were informed that the lesson was about calculating the volume of prisms and a cylinder (as a special type of prism). In his presentation, the teacher described the volume of a cube by relating it to the amount of fluids that can fill it. He then gave the formula:

\section{Area of a cube $=$ base area $\times$ height}

The teacher indicated that the same formula applies to the volume of cuboid. The activity was not given at this stage.

Triangular prism was then drawn on the board (Figure 8) by the teacher and he showed students that its base is an isosceles triangle. The students were to explain how to find the area of a triangle. One student raised up his hand and explained that the area is found by calculating half base by the height. He added that height is found by using the Pythagoras theorem. Others were not familiar with the way the area of the isosceles triangle had to be calculated, but few were aware of the properties of the isosceles triangle and they were comparing it with the right-angled triangle. They were operating at the directed orientation phase of the analysis level. The volume of the triangular prism was found by multiplying the area of base by height. The teacher further explained that the height has to be perpendicular to the base (see Figure 8).

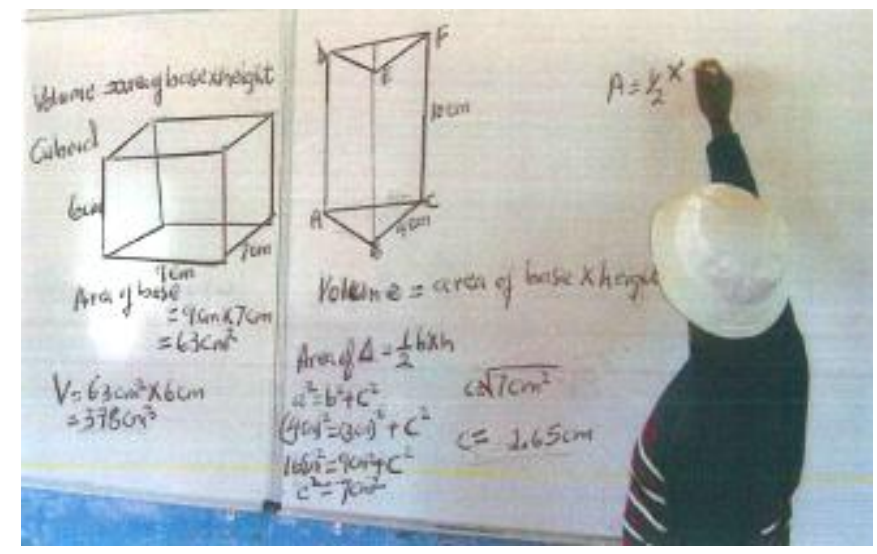

Figure 8. Teacher's presentation on calculating the volume of cuboid and triangular prism

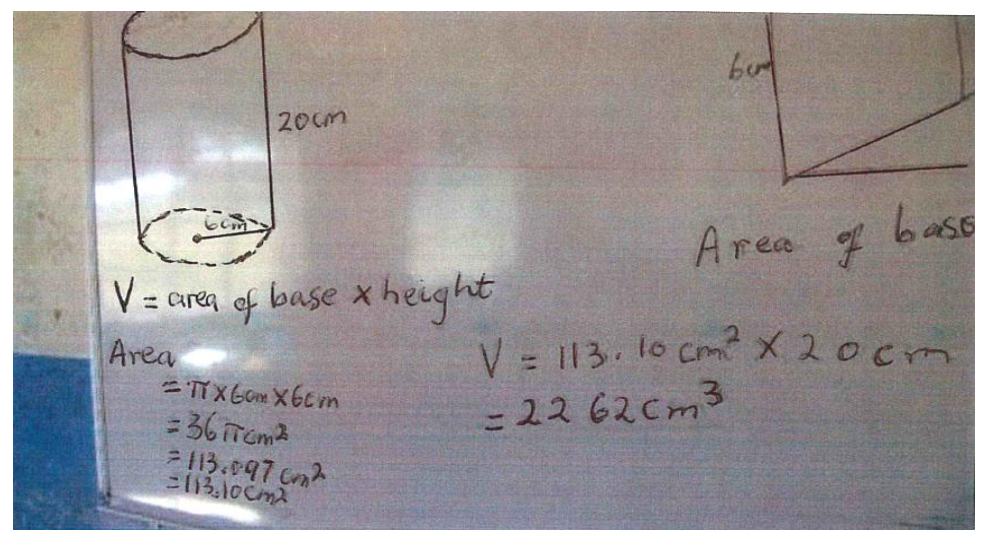

Figure 9. Teacher's presentation on calculating the volume of a cylinder 
The teacher here just used the formula to calculate the volume of a cylinder (Figure 9). The answer was given in cubic centimeters and the students were instructed to convert cubic centimeters to cubic meters, but the students could not convert the units. The teacher did the calculations for them. The activity was then given (as shown in Figure 10).

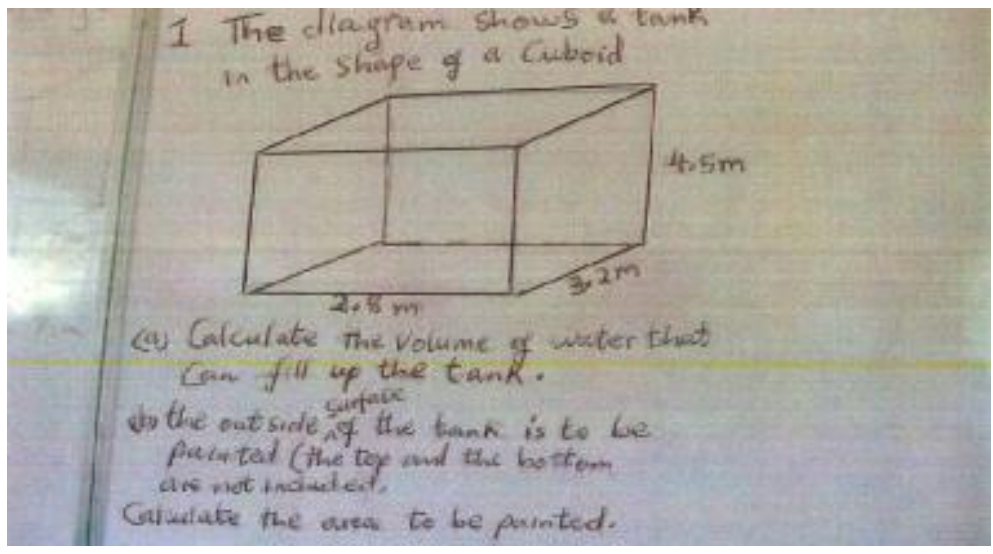

Figure 10. Activity on calculating volume and area of a cuboids

This activity was supposed to be done on the board. Before performing the activity, students discussed it in groups, then one student went to the board and wrote the answer for the first part of the activity without communicating with others (see Figure 11). The whole class agreed that she got the correct answer. This showed that they were operating at the directed/guided orientation phase of the analysis level. The second student wrote the solution for the second part of the activity (see Figure 12). The teacher, together with students, agreed that the answer was also correct.

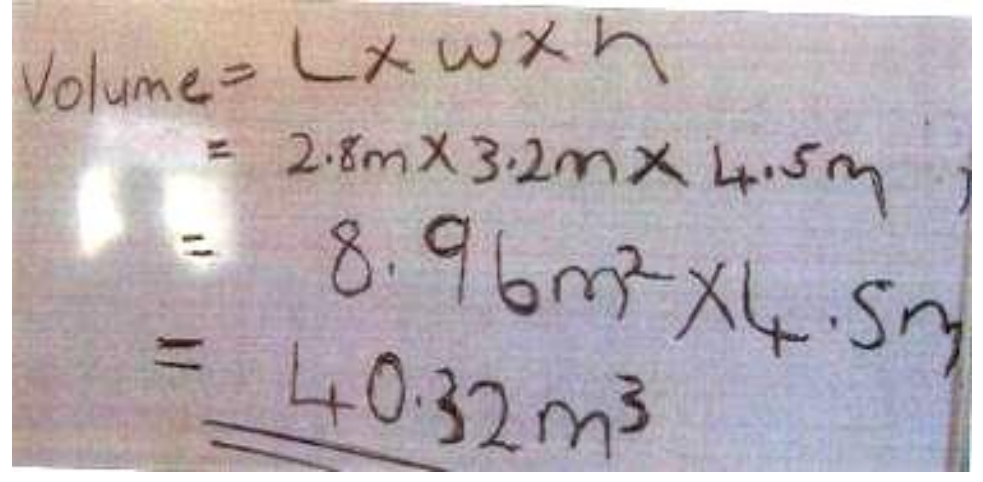

Figure 11. Answer given by the student for part one of the activity

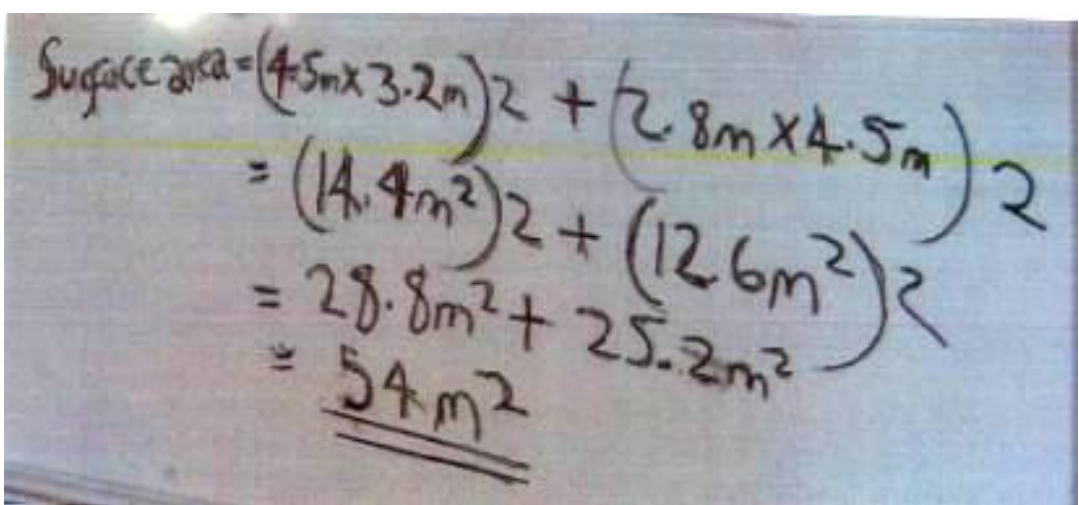

Figure 12. Answer given by the student for part two of the activity 
The teacher concluded the lesson by making the students aware that all what they did in previous lessons led them to the concept of volume of 3D geometric shapes. The teacher was interviewed as follows:
Researcher
Can you please explain why you put more focus on the volume of prisms like cuboids, triangular prism, and cylinder?
Teacher
The prism and the cylinder are the important shapes since there are some shapes that are related to them. For example, a pyramid is related to a prism (that is one can get a pyramid out of a prism) and a cone is related to a cylinder in that volume of a cone is one-third of the volume of a cylinder. In the examination, more questions in geometry are asked based on prism and cylinder.
Researcher Is there any difference between a prism and a cylinder?
Teacher

\begin{abstract}
In fact, a cylinder is a prism, but I used to separate it from other prisms since it has a circular cross-section and a circle has no finite number of sides.
\end{abstract}

The teacher was aware that the circle has no finite number of sides, while the polygons have a finite number of sides from which they are named. This knowledge seemed to have been important to him in his instruction. The demands of the examination seemed to have also influenced the teaching. Students were, however, just given the relationship between the solids (e.g., a cone and a cylinder) without being actively involved in finding out the relationships by themselves. Students were denied the opportunity of free-orientation and also the ability to form relationships between concepts (informal deduction).

From the observations made, we could argue that the instruction was slightly aligned to the Van Hiele phases of learning. The transition from one level of thinking to another was not achieved by providing the opportunities of learning for all the phases. This shows that there were some deficiencies in the way the instruction was organized in accordance with the Van Hiele theory. It could be partly the reason (although a case study) why students in Lesotho high schools do not perform well in geometry, as indicated by the examiners' reports.

\section{Discussions}

As in the case of Robichaux-Davis and Guarino (2016), the teacher in the reported study had some areas which had to be improved under content and pedagogy. For example, he made students generalize the relationship between vertices, edges, and faces by focusing on one set of numbers instead of all sets of numbers that were given in order to discover a more valid pattern. The teacher also seemed not to give students enough time to think about the question or activity but instead started giving students either some hints or show them how the answer could be obtained. This denied the students an opportunity to perform the tasks independently (free orientation phase). The teacher did not give students a chance to summarize the main points covered in the lesson (integration phase). He seemed to consider this to be his part, whereas, in a lesson, it was the learners who were to be given instruction that enabled them to master the phases of learning in order to transit from one level of thinking to another. In addition they are also similar to the results of the control groups of Abu and Abidin ( $\underline{2013}$ ), Alex and Mammen (2016), and Armah et al. (2018). They further have close resemblance with those of the Nigerian High schools by Atebe and Schäfer (2011) in terms of inadequate exposure of students to all the five phases.

In Luneta (2014), teachers reflected some subject matter knowledge inadequacies which landed them at a lower level of geometric thinking. There were, however, a few such errors in the reported study (e.g., premature generalization on how the faces, vertices, and edges of 3D shapes are related). As already highlighted, content problems were also observed in the study of Robichaux-Davis and Guarino (2016). This is an indication that 
although the knowledge of content is necessary, awareness of the existence of the Van Hiele phases seems to be a requirement for the meaningful transition between levels.

\section{Conclusion}

The Van Hiele theory of geometric thought has been useful and applicable in analyzing the teacher's methods of instruction in teaching geometry to the final year students in one high school in Lesotho. Among the implications for the study, we suggest that the teacher trainees should be exposed to theories such as the Van Hiele theory of geometric thought during their training. This is in order to make them aware of all the phases required to help learners transit from one level of geometric thought to another. The suggested phase-based teaching should also take into consideration the methods of teaching that will facilitate this to happen.

\section{Acknowledgment}

We would like to register our sincere gratitude to the participants of the study. In particular, the teacher who selflessly allowed us to observe and interview him. We are also indebted to the students for the important role they played in making this study a success. In addition we are highly grateful to the principal of the school for granting us permission to conduct this study.

\section{Bibliography}

Abdullah, A. H., \& Zakaria, E. (2013). The effects of Van Hiele' phases of learning geometry on students' degree of acquisition of Van Hiele levels. Social and Behavioral Sciences, 102, 251 - 266. https://doi.org/10.1016/j.sbspro.2013.10.740

$\mathrm{Abu}$, M. S.,\& Abidin, Z. Z. (2013). Improving the levels of geometric thinking of secondary students using geometry learning video based on Van Hiele theory. International Journal of Evaluation and Research in Education, 2(1), 16-22. http://dx.doi.org/10.11591/ijere.v2i1.1935

Alex, J. K., \& Mammen, K. J. (2016). Lessons Learnt from Employing van Hiele Theory Based Instruction in Senior Secondary School Geometry Classrooms. Eurasia Journal of Mathematics, Science \& Technology Education, 12(8), 2223-2236. http://doi.org/10.12973/eurasia.2016.1228a

Alex, J. K., \& Mammen, K. J. (2018). Students' understanding of geometry terminology through the lens of Van Hiele theory, Pythagoras, 39(1), a376. https://doi.org/10.4102/pythagoras.v39i1.376

Amidu, B., \& Nyarko, J. (2019). Van Hiele geometric thinking levels of junior high school students of Atebubu Municipality in Ghana.African Journal of Educational Studies in Mathematics and Sciences, 15, 39-50. https://dx.doi.org/10.4314/ajesms.v15i1.4

Armah, R. B., Cofie, P. O., \& Okpoti, C. A. (2017). The Geometric Thinking Levels of Preservice Teachers in Ghana. Higher Education Research, 2(3), 98-106.

Armah, R. B., Cofie, P. O., \& Okpoti, C. A. (2018). Investigating the Effect of Van Hiele phasebased instruction on pre-service teachers' geometric thinking. International Journal of Research in Education and Science, 4(1), 314-330.

Armah, R. B., \& Kissi, P. S. (2019). Use of the van Hiele Theory in Investigating Teaching Strategies used by College of Education Geometry Tutors. EURASIA Journal of Mathematics, Science and Technology Education, 2019, 15(4), 1305-8223. https://doi.org/10.29333/ejmste/103562 
Atebe, H. U.,\& Schäfer, M. (2011). The nature of geometry instruction and observed learning-outcomes opportunities in Nigerian and South African high schools. Education African Journal of Research in Mathematics, Science and Technology, 15(2), 191-204. https://doi.org/10.1080/10288457.2011.10740712

Bora, A., \& Ahmed, S. (2018). Secondary school students' attitude towards their learning geometry: A survey of DIphu Town secondary schools. International Journal of Research and Analytic Review, 5(3), 265 - 267. Retrieved from https://eric.ed.gov/?id=ED590512

Connolly, S. (2010). The impact of Van Hiele-based geometry instruction of students understanding. (Mathematical and Computing Sciences Masters, paper 97. St John Fisher College. Retrieved from https://fisherpub.sjfc.edu/mathcs etd masters/97

Examinations Council of Lesotho (2017). Mathematics examiners' reports, syllabus 0178/4. Maseru: Lesotho.

Examinations Council of Lesotho (2018). Mathematics examiners' reports, syllabus 0178/3. Maseru: Lesotho.

Fitriyani, H., Widodo, S. A., \& Hendroanto, A. (2018). Students' geometric thinking based on Van Hiele's theory. Infinity Journal of Mathematics Education, 7(1), 55-60. https://doi.org/10.22460/infinity.v7i1.p55-60

Howse, T. D., \& Howse, E. M. (2015). Linking the Van Hiele theory to instruction. Teaching children mathematics, 21(5),

305-313. https://doi.org/10.5951/teacchilmath.21.5.0304

Luneta, K. (2014). Foundation phase teachers' (limited) knowledge of geometry. South African Journal of Education, 4(3), 71-86.

National Curriculum Development Centre and Examinations Council of Lesotho (2019). Lesotho General Certificate of Secondary Education Syllabus Mathematics 0178. Maseru: National Curriculum Development Centre and Examinations council of Lesotho.

Nisawa, Y. (2018). Applying Van Hiele's Levels to basic research on the difficulty factors behind understanding functions. International Electronic Journal of Mathematics Education 13(2), 61-65. https://doi.org/10.12973/iejme/2696

Robichaux-Davis, R. R., \& Guarino, A. J. (2016). Assessing Elementary Pre-service Teachers' Knowledge for Teaching Geometry. International Journal of Mathematics and Statistics Invention, 4(1), 12-20. Retrieved from https://www.ijmsi.org/Papers/Volume.4.Issue.1/C041012020.pdf

Russell, D. (2014). What is Geometry? Retrieved from http://math.about.com/od/geometry/a/whygeom.htm

Vojkuvkova, I. (2012). The van Hiele Model of Geometric Thinking. WDS'12 Proceedings of Contributed Papers, Part I, 72-75. ISBN 978-80-7378-224-5 